University of Montana

ScholarWorks at University of Montana

$11-2015$

\title{
Spatial aspects of tree mortality strongly differ between young and old-growth forests
}

\author{
Andrew J. Larson \\ University of Montana - Missoula, a.larson@umontana.edu \\ James A. Lutz \\ Utah State University \\ Daniel C. Donato \\ Washington State Department of Natural Resources \\ James A. Freund \\ University of Washington - Seattle Campus \\ Mark E. Swanson \\ Washington State University \\ See next page for additional authors \\ Follow this and additional works at: https://scholarworks.umt.edu/forest_pubs \\ Part of the Forest Management Commons \\ Let us know how access to this document benefits you.
}

\section{Recommended Citation}

Andrew J. Larson, James A. Lutz, Daniel C. Donato, James A. Freund, Mark E. Swanson, Janneke HilleRisLambers, Douglas G. Sprugel, and Jerry F. Franklin 2015. Spatial aspects of tree mortality strongly differ between young and old-growth forests. Ecology 96:2855-2861. http://dx.doi.org/10.1890/ 15-0628.1

This Report is brought to you for free and open access by the Forest Management at ScholarWorks at University of Montana. It has been accepted for inclusion in Forest Management Faculty Publications by an authorized administrator of ScholarWorks at University of Montana. For more information, please contact scholarworks@mso.umt.edu. 


\section{Authors}

Andrew J. Larson, James A. Lutz, Daniel C. Donato, James A. Freund, Mark E. Swanson, Janneke HillRisLambers, Douglas G. Sprugel, and Jerry F. Franklin 


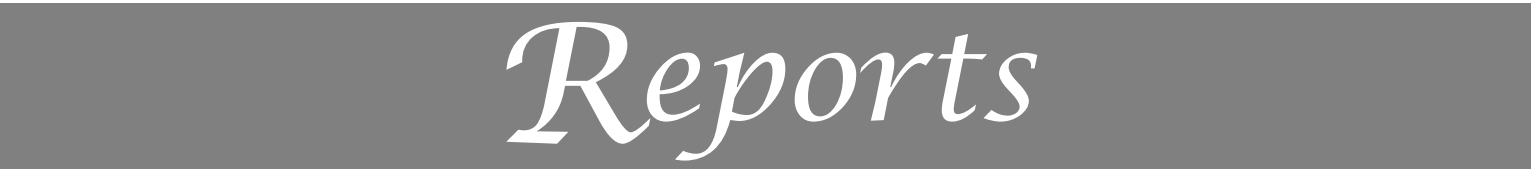

Ecology, 96(11), 2015, pp. 2855-2861

(C) 2015 by the Ecological Society of America

\title{
Spatial aspects of tree mortality strongly differ between young and old-growth forests
}

\author{
Andrew J. Larson,,${ }^{1,7}$ James A. Lutz,${ }^{2}$ Daniel C. Donato, ${ }^{3}$ James A. Freund,${ }^{4}$ Mark E. Swanson, ${ }^{5}$ \\ Janneke HilleRisLambers, ${ }^{6}$ Douglas G. Sprugel, ${ }^{4}$ and Jerry F. Franklin ${ }^{4}$ \\ ${ }^{1}$ Department of Forest Management, University of Montana, Missoula, Montana 59812 USA \\ ${ }^{2}$ Wildland Resources Department, Utah State University, 5230 Old Main Hill, Logan, Utah 84322-5230 USA \\ ${ }^{3}$ Washington State Department of Natural Resources, 1111 Washington St. SE, Box 47014, Olympia, Washington 98504 USA \\ ${ }^{4}$ School of Environmental and Forest Sciences, Box 352100, University of Washington, Seattle, Washington 98195-2100 USA \\ ${ }^{5}$ School of the Environment, Washington State University, Pullman, Washington 99164-2812 USA \\ ${ }^{6}$ Department of Biology, Box 351800, University of Washington, Seattle, Washington 98195-1800
}

\begin{abstract}
Rates and spatial patterns of tree mortality are predicted to change during forest structural development. In young forests, mortality should be primarily density dependent due to competition for light, leading to an increasingly spatially uniform pattern of surviving trees. In contrast, mortality in old-growth forests should be primarily caused by contagious and spatially autocorrelated agents (e.g., insects, wind), causing spatial aggregation of surviving trees to increase through time. We tested these predictions by contrasting a threedecade record of tree mortality from replicated mapped permanent plots located in young $(<60$-year-old) and old-growth ( $>300$-year-old) Abies amabilis forests. Trees in young forests died at a rate of $4.42 \%$ per year, whereas trees in old-growth forests died at $0.60 \%$ per year. Tree mortality in young forests was significantly aggregated, strongly density dependent, and caused live tree patterns to become more uniform through time. Mortality in old-growth forests was spatially aggregated, but was density independent and did not change the spatial pattern of surviving trees. These results extend current theory by demonstrating that densitydependent competitive mortality leading to increasingly uniform tree spacing in young forests ultimately transitions late in succession to a more diverse tree mortality regime that maintains spatial heterogeneity through time.
\end{abstract}

Key words: Abies amabilis; density dependence; forest structural development; long-term studies; oldgrowth forest; Pacific silver fir; self-thinning; succession; tree mortality; western Cascade Range, Washington, USA.

\section{INTRODUCTION}

Spatial heterogeneity in the horizontal distribution of trees develops as forests progress through structural development following stand-replacement disturbance, which is linked to key ecosystem functions such as provision of habitat for biodiversity (Franklin and Van Pelt 2004). Tree mortality is thought to be a principal driver of increasing spatial heterogeneity (Franklin et al. 2002). Although changes in the rates and causes of tree mortality over the course of succession are increasingly well understood (Lutz and Halpern 2006, Harmon and Pabst 2015), spatial aspects of tree mortality, and how

Manuscript received 7 April 2015; revised 2 July 2015; accepted 21 July 2015. Corresponding Editor: J. J. Battles.

${ }^{7}$ E-mail: a.larson@umontana.edu they vary as forests mature, have received comparatively little study.

The dominant modes and spatial attributes of tree mortality in forests are hypothesized to depend on structural development stage (Franklin et al. 1987, Peet and Christensen 1987). Competition among trees intensifies following tree canopy closure in young forests, which should to lead to density-dependent competitive mortality (Peet and Christensen 1987). Density-dependent mortality refers to the situation in which mortality rates are higher in localized regions of higher tree density (number per unit area). Such competitive mortality is expected to cause the spatial pattern of surviving trees to become increasingly uniform through time (Laessle 1965), and some empirical studies of young tree populations undergoing self-thinning have confirmed this prediction (e.g., Kenkel et al. 1997). However, as 
TABLE 1. Predictions (P1-3) for spatial aspects of tree mortality in young and old-growth forests, where $(r)$ is distance and $g$ is the pair correlation function; subscripts 1 and d refer to live and dead trees, respectively.

\begin{tabular}{|c|c|}
\hline Prediction & Ecological basis and test statistic \\
\hline P1) Spatial pattern of mortality & $g_{\mathrm{d}, \mathrm{d}}(r)$ \\
\hline Young: spatially aggregated mortality & $\begin{array}{l}\text { Mortality concentrated in locally dense tree clumps (Kenkel } \\
\text { 1988, Kenkel et al. 1997, Getzin et al. 2008). }\end{array}$ \\
\hline Old-growth: spatially aggregated mortality & $\begin{array}{l}\text { Spatially contagious or spatially autocorrelated mortality } \\
\text { agents result in aggregations of dying trees (Franklin et al. } \\
\text { 2002, Worrall et al. 2005). }\end{array}$ \\
\hline P2) Spatial context of mortality & $g_{\mathrm{d}, \mathrm{d}+1}(r)-g_{1, \mathrm{~d}+1}(r)$ \\
\hline $\begin{array}{l}\text { Young: initial neighborhoods of dying trees more crowded } \\
\text { than those of surviving trees }\end{array}$ & $\begin{array}{l}\text { Mortality is primarily density-dependent due to competition } \\
\text { (Laessle 1965, Peet and Christensen 1987). }\end{array}$ \\
\hline $\begin{array}{l}\text { Old-growth: initial neighborhoods of dying and surviving } \\
\text { trees do not differ }\end{array}$ & $\begin{array}{l}\text { Predominance of agent-based mortality overwhelms signal of } \\
\text { any density-dependent mortality (Acker et al. 1996, Worrall } \\
\text { et al. 2005). }\end{array}$ \\
\hline P3) Spatial outcome of mortality & $g_{1,1}(r)-g_{1+\mathrm{d}, 1+\mathrm{d}}(r)$ \\
\hline $\begin{array}{l}\text { Young: spatial pattern of surviving trees more uniform } \\
\text { than initial condition }\end{array}$ & $\begin{array}{l}\text { Density-dependent mortality causes spatial pattern of } \\
\text { surviving trees to become increasingly uniform (Laessle } \\
\text { 1965, Kenkel et al. 1997). }\end{array}$ \\
\hline $\begin{array}{l}\text { Old-growth: spatial pattern of surviving trees more } \\
\text { aggregated than initial condition }\end{array}$ & $\begin{array}{l}\text { Spatially contagious or spatially autocorrelated mortality } \\
\text { increases spatial aggregation (Acker et al. 1996, Franklin } \\
\text { and Van Pelt 2004). }\end{array}$ \\
\hline
\end{tabular}

the pioneer tree cohort approaches maximum crown spread, the relative importance of density-dependent competitive mortality is thought to decline (Getzin et al. 2006), being replaced by relatively higher rates of noncompetitive tree mortality (e.g., caused by insects, disease, or wind). Such noncompetitive tree mortality is hypothesized to occur primarily in spatially aggregated patterns (Acker et al. 1996, Franklin et al. 2002), thereby increasing spatial heterogeneity of the surviving tree population in later structural development stages.

Our objectives were to determine whether and how spatial aspects of tree mortality differ between young and old-growth forests (Table 1) in order to better understand the demographic mechanisms that generate spatial heterogeneity during forest structural development. Forest structural development theory suggests that spatial aspects of tree mortality change during succession (Table 1), but questions remain because past empirical tests have been based on (1) a one-time inventory of live and dead trees (e.g., Kenkel 1988); (2) longitudinal observations of tagged tree populations, but which lacked replicate plots (e.g., Lutz et al. 2014); or (3) replicated, longitudinal designs implemented only at a single successional stage (e.g., Das et al. 2008). Here, we overcome these limitations with a three-decade, spatially explicit record of tree mortality obtained by following individually tagged trees in replicated plots located in young and old-growth forests of the same type. We tested predictions (Table 1) for the spatial pattern (P1), spatial context (P2), and spatial outcome (P3) of tree mortality in young and old-growth forests. Spatial pattern refers to the arrangement of the dying trees themselves (e.g., clustered or dispersed), spatial context refers to the neighborhood around dying trees (e.g., densely or sparsely populated), and spatial outcome refers to the changing patterns of surviving trees as a result of mortality (e.g., whether the spatial pattern becomes more uniform or aggregated). By considering all three factors, we can better interpret the mechanisms that may underlie differences in mortality between young and old-growth forests.

\section{Methods}

The study sites are located in Abies amabilis Zone (Franklin and Dyrness 1988) forests at middle and upper elevations in the western Cascade Range, Washington, USA. Abies amabilis (Pacific silver fir) forests occur on sites characterized by cool temperatures and abundant precipitation; much of the precipitation falls as snow and accumulates in winter snowpacks of 1$4 \mathrm{~m}$ (Grier et al. 1981, Franklin and Dyrness 1988). Common tree associates include Abies procera, Pseudotsuga menziesii, Thuja plicata, and Tsuga heterophylla at lower and middle elevations, and Cupressus nootkatensis and Tsuga mertensiana at upper elevations (Franklin and Dyrness 1988). Canopy heights in mature stands range from $25 \mathrm{~m}$ to $50 \mathrm{~m}$ depending on site quality. The dominant disturbance regime is infrequent, high-severity fires with return intervals of $\sim 200-700 \mathrm{yr}$ (Agee 1993). Forest development following standreplacement disturbance progresses relatively predictably through stages of cohort initiation, canopy closure, self-thinning and biomass accumulation, and understory reinitiation, culminating in a structurally complex oldgrowth stage (Oliver et al. 1985). This pattern of forest structural development is characteristic of many other forest ecosystems that experience stand-replacement disturbance (Franklin et al. 2002). Occasional tephra deposition is another disturbance process in the volcanic Cascade Range that can have strong negative effects on Abies amabilis growth and survival (Segura et al. 1994), 
but none of the study sites experienced tephra deposition during the period of study.

The eight young forest plots were located in the Findley Lake Research Natural Area within the Cedar River Watershed $\left(47.3208^{\circ} \mathrm{N}, 121.5928^{\circ} \mathrm{W}\right)$ at an elevation of $1140 \mathrm{~m}$. The stand originated from the release of advance regeneration and establishment of new tree seedlings following clearcut harvest (without slash burning) of the overstory in 1955. In 1978, Grier et al. (1981) established eight $6 \times 6 \mathrm{~m}$ plots in which all live trees were tagged and their stem diameters were measured at $15 \mathrm{~cm}$ above ground level. In 1985, the plots were re-censused, the locations of the original tagged trees were mapped (Appendix: Fig. A1), and survival and stem growth of each tree was assessed (96.2\% of the original 1978 population was found in 1985). Subsequently, survival of every tagged tree was assessed annually from 1986 to 2001, and again in 2009. Initial and final sample sizes and species compositions are provided in the Appendix: Table A1.

The old-growth study sites are located in Mount Rainier National Park, USA, (centered around $46.8522^{\circ}$ $\left.\mathrm{N}, 121.7594^{\circ} \mathrm{W}\right), \sim 50-60 \mathrm{~km}$ south of the young forest plots. At least 300 years have passed since the most recent stand-replacement wildfire at each of the study sites. The old-growth plots are distributed throughout the Abies amabilis Zone at elevations ranging from 841 $\mathrm{m}$ to $1451 \mathrm{~m}$. In 1977 and 1978, eight 1-ha $(100 \times 100 \mathrm{~m})$ plots were installed in which all trees with $\mathrm{dbh} \geq 15 \mathrm{~cm}$ were identified, mapped (Appendix: Fig. A2), and tagged. Plots were censused every 4-10 years (mean 5.7 years), with the most recent census occurring in either 2007 or 2008. For detailed descriptions of the oldgrowth sites, see Larson and Franklin (2010). Initial and final sample sizes and species compositions are provided in the Appendix: Table A1.

We calculated annualized mortality rate, $m$, for the initial population of tagged trees (all species combined) over the entire period of study as

$$
m=1-\left(N_{t} / N_{0}\right)^{1 / t}
$$

where $N_{0}$ is the initial number of live trees, $N_{t}$ is the total number of those trees remaining at the end of the study period, and $t$ is the number of years between the initial and final censuses.

We quantified spatial aspects of tree mortality using spatial statistics based on the univariate, $g(r)$, and bivariate, $g_{12}(r)$, forms of the pair correlation function, which is the derivative of Ripley's $K$ function (Wiegand and Moloney 2004). To capture the full statistical power of our data, we used replicated point pattern analysis methods (Baddeley et al. 1993, Raventós et al. 2010). We used random labeling in a marked point process framework to test all three predictions (Table 1). Random labeling (i.e., random mortality) is the appropriate null model for events that affect a posteriori members of an established population, such as mortality (Goreaud and Pélissier 2003). We permuted tree status at the final census ( $n=999$ simulations for each analysis) to construct null distributions of the summary spatial statistics. Random labeling was implemented at the individual plot scale, and the relevant spatial statistic was estimated for each plot and then combined into a single estimate, as in Raventós et al. (2010).

To test for departures from random mortality (Table $1)$, we used the statistics $g_{\mathrm{d}, \mathrm{d}}(r), g_{\mathrm{d}, \mathrm{d}+1}(r)-g_{1, \mathrm{~d}+1}(r)$, and $g_{1,1}(r)-g_{1+\mathrm{d}, 1+\mathrm{d}}(r)$. Subscripts denote tree status: live (1) or dead (d) at the end of the study. We used $g_{\mathrm{d}, \mathrm{d}}(r)$ to test for spatial structure in the locations of trees that died (P1). Positive (or negative) departures relative to random mortality indicate spatial aggregation (or dispersion) in the locations of dead trees (Raventós et al. 2010). Density-dependent mortality (P2) was evaluated with $g_{\mathrm{d}, \mathrm{d}+1}(r)-g_{1, \mathrm{~d}+1}(r)$, which compares the initial neighborhoods of trees that died and survived (Raventós et al. 2010). Positive (or negative) values indicate that dead trees had more (or less) crowded initial neighborhoods than survivors. Spatial outcomes of mortality (P3) were assessed by comparing the final pattern of surviving trees against the initial pattern of all (live + dead) trees using $g_{1,1}(r)-g_{1+\mathrm{d}, 1+\mathrm{d}}(r)$. Positive (or negative) departures indicate that mortality caused the pattern of live trees to become more (or less) aggregated (Das et al. 2011).

We used the Diggle-Cressie-Loosmore-Ford (DCLF) goodness-of-fit test (Loosmore and Ford 2006, Baddeley et al. 2014) for inference. Because dominant tree sizes differ between our young and old-growth sites, we analyzed patterns at inter-tree distances up to $1.0 \mathrm{~m}$ in young forests, and up to $4.0 \mathrm{~m}$ in old-growth forests. These distances reflect our estimates of the maximum effective tree neighborhood radius and are based on dominant tree crown radii for forests of these ages (Sorrensen-Cothern et al. 1993, Bechtold 2004, Larson and Churchill 2008). All analyses were implemented in R (R Core Team 2014). Spatial statistics were estimated using the spatstat package (Baddeley and Turner 2005).

\section{ReSUlts}

The average mortality rate in young forest plots was more than seven times greater than in old-growth plots. Trees died at an average rate of $4.42 \%$ per year (range $3.33-6.78 \%$ per year) in young plots and $0.60 \%$ per year (range $0.37-0.86 \%$ per year) in old-growth plots (Appendix: Table A2). Mortality in young plots was caused primarily, but not exclusively, by suppression arising from competition for light (Sorrensen-Cothern 1993), and was concentrated in the smallest size classes (Appendix: Fig. A3). Mortality agents in the old-growth plots included suppression, biological agents, and physical processes such as snow, wind, and crushing by falling trees and tree parts (Larson and Franklin 2010), and tree mortality was relatively evenly distributed across the tree size distribution (Appendix: Fig. A4).

Trees that died were more aggregated than expected under random mortality (Fig. $1 \mathrm{C}, \mathrm{D})$ in both young $(P=$

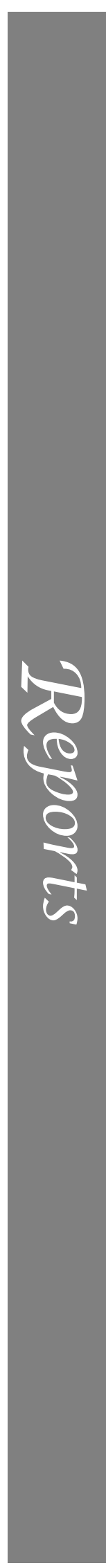


A) Example conditions, young forest

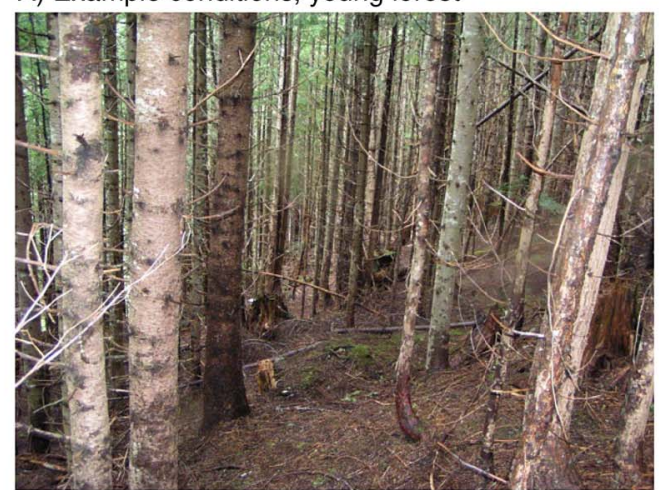

C) P1: Pattern of mortality, young

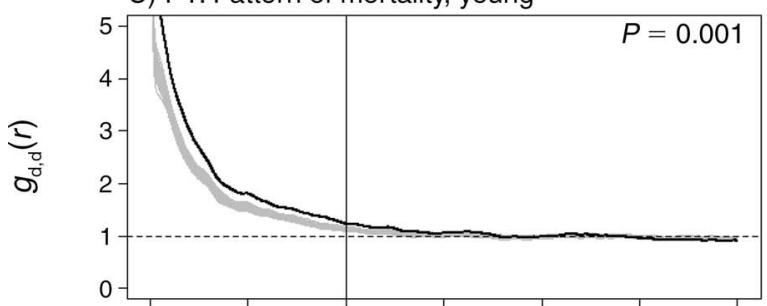

E) P2: Context of mortality, young

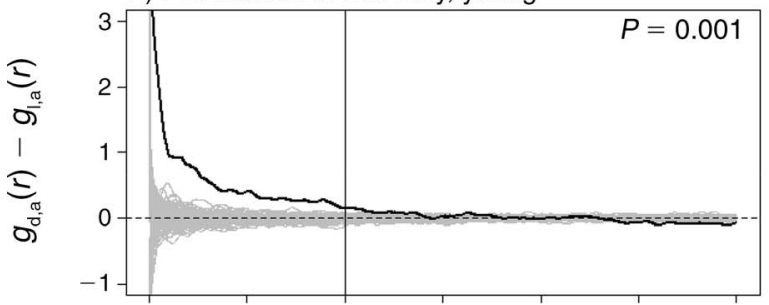

G) P3: Outcome of mortality, young

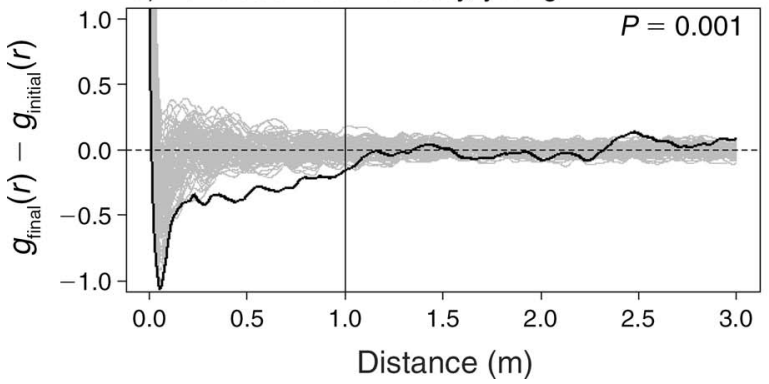

B) Example conditions, old-growth forest

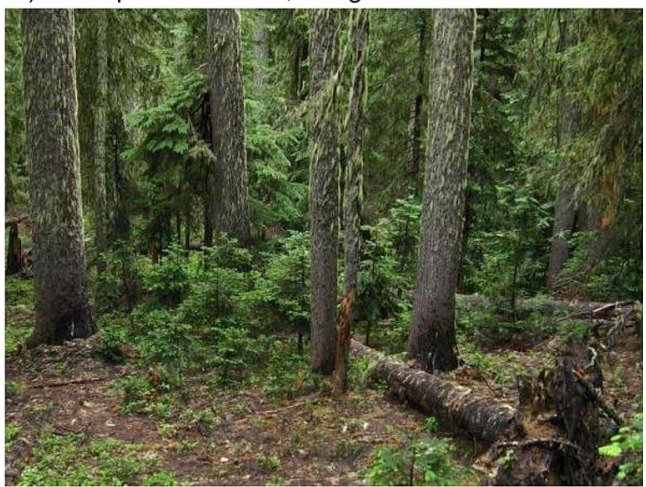

D) P1: Pattern of mortality, old-growth

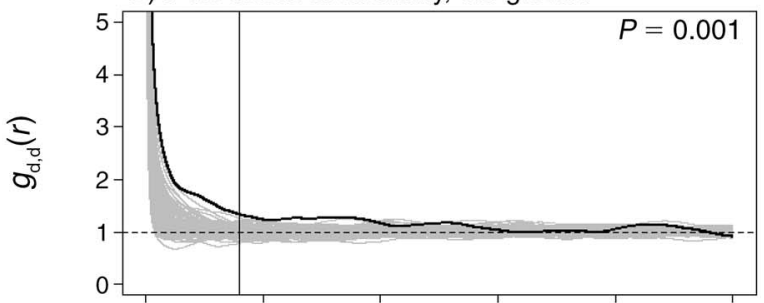

F) P2: Context of mortality, old-growth

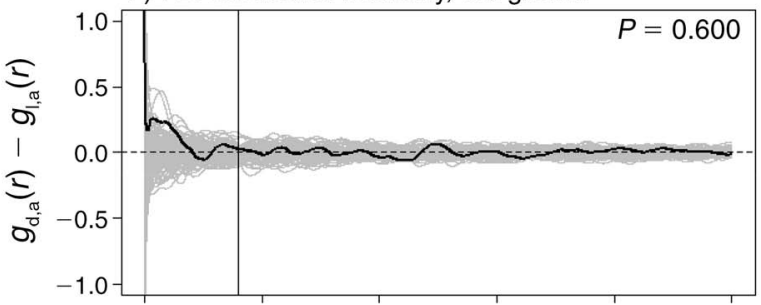

H) P3: Outcome of mortality, old-growth

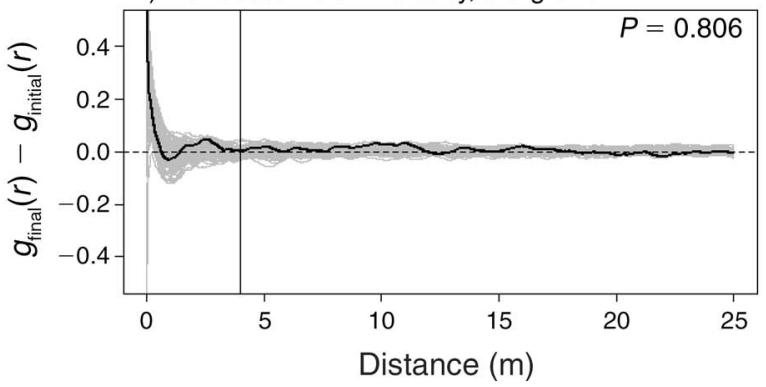

FIG. 1. (A, B) Stand structure and $(\mathrm{C}-\mathrm{H})$ spatial aspects of tree mortality in young and old-growth Abies amabilis forests. Forest development following stand-replacement disturbances in Abies amabilis forests progresses relatively predictably through stages of cohort initiation, canopy closure, self-thinning and biomass accumulation, and understory reinitiation, and ultimately culminates in a structurally complex old-growth stage (sensu Franklin et al. 2002). Here, young forests are examples of the selfthinning and biomass accumulation stage (A); old forests are examples of the structurally complex old-growth stage (B). (C-H) The empirical result $(n=8$ plots in young and old-growth forests, respectively; $(r)$ is distance, $g$ is the pair correlation function, subscripts 1, d, and a refer to live, dead, and all trees) is shown by the thick black line; light gray lines show simulations of random mortality. (C, D) Spatial pattern of mortality (P1) conditioned on the initial pattern of live trees; values above (or below) the simulation envelope indicate aggregated (or dispersed) mortality. (E, F) Spatial context of mortality (P2); values above (or below) the simulation envelope indicate that the initial neighborhoods of trees that died were more (or less) crowded than the initial neighborhoods of trees that survived. (G, H) Spatial outcome of mortality (P3) as the difference between final and initial pattern; values above (or below) the simulation envelope indicate that the pattern of surviving trees became more aggregated (or dispersed) due to mortality. $P$ values are based on the Diggle-Cressie-Loosmore-Ford goodness-of-fit test (Loosmore and Ford 2006, Baddeley et al. 2014) implemented at distances of $0-1.0 \mathrm{~m}$ in young forests and $0-4.0 \mathrm{~m}$ in old-growth forests (shown by the vertical line in panels $\mathrm{C}-\mathrm{H}$ ); these distances correspond to our estimates of the maximum effective tree neighborhood radius for these two stand ages. Photo credit: A. J. Larson. 
$0.001)$ and old-growth $(P=0.001)$ forests. Trees that died were more aggregated than expected at inter-tree distances up to about $1.0 \mathrm{~m}$ in young forests (Fig. 1C) and up to about $10 \mathrm{~m}$ in old-growth forests (Fig. 1D). All eight young plots had significantly aggregated mortality when analyzed individually (Appendix: Table A3), and mortality was significantly aggregated in four of the eight old-growth plots (Appendix: Table A3).

The spatial context of tree mortality differed strongly between young and old-growth forests (Fig. 1C, D). In young forests, the initial neighborhoods $(<1.0 \mathrm{~m})$ of trees that died were significantly more crowded than those of surviving trees; this is clear evidence for densitydependent mortality. In contrast, the initial neighborhoods $(<4.0 \mathrm{~m})$ of trees that survived and trees that died were not different (i.e., no different from random mortality) in old-growth forests $(P=0.600)$. In all eight replicate young plots, the trees that died during the study had significantly more crowded initial neighborhoods $(<1.0 \mathrm{~m})$ than trees that survived to the end of the study (Appendix: Table A3). Density-dependent mortality was apparent in only one (AM16) of the oldgrowth plots when analyzed individually (Appendix: Table A3).

The effect of tree mortality on the spatial pattern of surviving trees differed between young and old-growth sites (Fig. 1E, F). Live tree patterns became increasingly uniform $(P=0.001)$ as a result of density-dependent mortality in young forests. In contrast, there was no detectable change $(P=0.806)$ from initial to final live tree patterns in old-growth forests. Mortality caused tree patterns to become more uniform in four of eight young forest plots, and surviving tree patterns became more uniform in only a single old-growth plot, with no detectable change in the other seven plots (Appendix: Table A3).

\section{Discussion}

Our results suggest that spatial aspects of tree mortality change over the course of succession. All three predictions for young forests (Table 1) were upheld, indicating a dominant role of density-dependent competitive mortality, which caused the spatial pattern of surviving trees to become increasingly uniform relative to the initial condition. Although our young plots are relatively small in size and limited in geographic extent, our results are consistent with theory (Ford and Diggle 1981) and with previous results from young forests undergoing self-thinning (Kenkel et al. 1997). Furthermore, tree density and spatial pattern in widely distributed young forests of differing initial densities converge as they undergo self-thinning (Kashian et al. 2005). The predictions for old-growth forests (Table 1) were partially supported. We found evidence for spatially aggregated (P1), density-independent (P2) tree mortality, as predicted, but the spatial patterns of surviving trees (P3) did not become more aggregated through time.
Following stand initiation and canopy closure, density-dependent competitive mortality dominates the demographics of young forests (Franklin et al. 2002, Lutz and Halpern 2006, Harmon and Pabst 2015). This density-dependent mortality causes the spatially aggregated initial tree population (Appendix: Fig. A1) to become increasingly uniform during early stand development (e.g., Laessle 1965, Svoboda et al. 2010). In some cases, competitively based mortality may culminate in a spatially uniform pattern of surviving trees, for example as has been observed in young stands of the very shadeintolerant tree Pinus banksiana (Kenkel 1988, Kenkel et al. 1997). However, this outcome appears to be uncommon in many natural forests, including Abies amabilis forests (Larson and Churchill 2008), possibly because of the extreme shade tolerance (Antos et al. 2005) and crown plasticity of this species (SorrensenCothern et al. 1993). In many maturing young forests, a gradual decrease of spatial aggregation in the population of survivors is more common (e.g., Svoboda et al. 2010).

Results from previous studies of old-growth forests are highly variable and apparently contradictory. He and Duncan (2000) found evidence for density-dependent effects on tree survival based on spatial relationships between live and dead trees in a 250-year-old Pseudotsu$g a-T$ suga forest on Vancouver Island. In Sierra Nevada mixed-conifer forests, Das et al. (2011) found that trees that died had more crowded neighborhoods in nine of their 14 plots, but spatial analyses indicated that the pattern of residual live trees (c.f. P3 in Table 1) became more uniform in only three plots. Others have found less evidence for competitive mortality in old-growth forests. Acker et al. (1996) documented spatially random mortality for Abies procera in an old-growth AbiesPseudotsuga forest, contrary to their expectation of spatially aggregated mortality (based on the observation that root pathogens were responsible for a high portion of mortality events). Similarly, two recent studies in oldgrowth Pinus resinosa forests in Minnesota, USA, found overall spatially random mortality (Aakala et al. 2012, Silver et al. 2013). Some of these apparent discrepancies may arise from different protocols across studies, especially differing lower diameter limits. Standardizing protocols across sites and stand ages (e.g., tagging all stems with $\mathrm{dbh} \geq 1 \mathrm{~cm}$ ) will eliminate this potential source of error in the future.

We suggest that a more comprehensive assessment of tree mortality processes is needed, especially in oldgrowth forests. A diverse set of agents cause tree mortality in old-growth forests, including competitive suppression, insects and diseases, and physical damage caused by snow, wind, and other falling trees (Larson and Franklin 2010, Das et al. 2011, Holzwarth et al. 2013, Acker et al. 2015). Many of the noncompetitive mortality agents active in old-growth forests spread through contagious processes, thereby increasing spatial heterogeneity in the surviving tree populations (e.g., Worrall et al. 2005). It is not surprising, however,

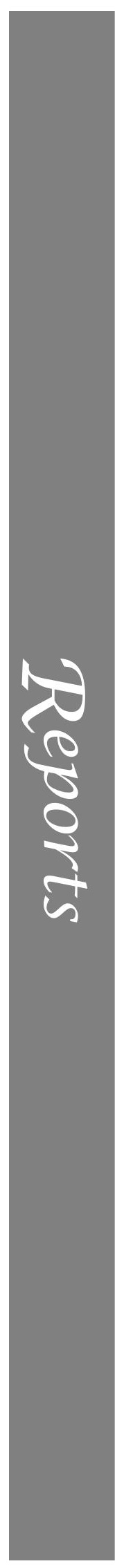


that density-dependent mortality is occasionally inferred from spatial analyses of tree mortality in mature (Vacek and Leps 1996, Ward et al. 1996) and oldgrowth (Das et al. 2011, Lutz et al. 2014) forests. Small trees (the subpopulations most strongly affected by competitive stress) are abundant in old-growth forests and density-dependent suppression mortality is definitely part of the overall tree mortality regime (Larson and Franklin 2010, Holzwarth et al. 2013). Some of the mortality events in our old-growth study sites were undoubtedly synchronous and spatially autocorrelated (e.g., Aakala et al. 2007), generating a more clumped pattern of surviving trees. Other mortality events probably were due to density-dependent factors, e.g., competitive stress in patches of shade-tolerant trees that recruited in canopy gaps (which may be underestimated in our data, given the $15 \mathrm{~cm}$ dbh lower size limit in our old-growth plots), which generate a more dispersed pattern of surviving trees (Ward et al. 1996, Wolf 2005, Lutz et al. 2014). We propose that the net combined effect of these diverse mortality agents, both density dependent and density independent, is to generate spatial patterns of tree mortality that are frequently indistinguishable from randomness, especially in the larger tree size classes.

Our most important finding is the striking difference in spatial aspects of tree mortality in young vs. oldgrowth forests. Our data show that the primarily density-dependent competitive mortality leading to increasingly uniform tree spacing in young forests (Laessle 1965, Kenkel 1988, Kenkel et al. 1997) ultimately gives way to a more diverse suite of mortality processes (Larson and Franklin 2010, Holzwarth et al. 2013) that create and maintain spatial heterogeneity in old-growth forests. This is important because current theory overwhelmingly emphasizes the development of spatial uniformity due to competitive self-thinning, without consideration of how spatial aspects of tree mortality change in later successional stages.

The next research problem that follows from our work is partitioning the tree mortality regime in oldgrowth forests into the specific constituent mortality agents and processes (sensu Larson and Franklin 2010, Holzwarth et al. 2013) in order to determine their individual spatial signatures and relative contribution to the generation and maintenance of spatial heterogeneity. Solving this problem will require tree mortality data from large mapped plots, collected with standardized protocols and careful attribution of proximate mortality cause and predisposing factors (Stephenson et al. 2011). We expect that this approach will help to reconcile the contradictory results in the literature for spatial aspects of tree mortality in old-growth forests.

\section{ACKNOWLEDGMENTS}

We are grateful to Amy LaBarge and Rolf Gersonde for providing access to plots in the Cedar River Municipal Watershed, and to Mount Rainier National Park for permitting this study. We thank Adrian Baddeley for guidance on the replicated point pattern analyses.

\section{Literature Cited}

Aakala, T., S. Fraver, B. J. Palik, and A. W. D'Amato. 2012. Spatially random mortality in old-growth red pine forests of northern Minnesota. Canadian Journal of Forest Research 42:899-907.

Aakala, T., T. Kuuluvainen, L. De Grandpré, and S. Gauthier. 2007. Trees dying standing in the northeastern boreal oldgrowth forests of Quebec: spatial patterns, rates, and temporal variation. Canadian Journal of Forest Research 37:50-61.

Acker, S. A., J. R. Boetsch, M. Bivin, L. Whiteaker, C. Cole, and T. Philippi. 2015. Recent tree mortality and recruitment in mature and old-growth forests in western Washington. Forest Ecology and Management 336:109-118.

Acker, S. A., M. E. Harmon, T. A. Spies, and W. A. McKee. 1996. Spatial patterns of tree mortality in an old-growth Abies-Pseudotsuga stand. Northwest Science 70:132-138.

Agee, J. K. 1993. Fire ecology of Pacific Northwest forests. Island Press, Washington, D.C., USA.

Antos, J. A., H. I. Guest, and R. Parish. 2005. The tree seedling bank in an ancient montane forest: stress tolerators in a productive habitat. Journal of Ecology 93:536-543.

Baddeley, A., P. J. Diggle, A. Hardegen, T. Lawrence, R. K. Milne, and G. Nair. 2014. On tests of spatial pattern based on simulation envelopes. Ecological Monographs 84:477489.

Baddeley, A., R. A. Moyeed, C. V. Howard, and A. Boyde. 1993. Analysis of a three-dimensional point pattern with replication. Applied Statistics 42:641-668.

Baddeley, A., and R. Turner. 2005. Spatstat: an R package for analyzing spatial point patterns. Journal of Statistical Software 12(6): 1-42.

Bechtold, W. A. 2004. Largest-crown-width prediction models for 53 species in the western United States. Western Journal of Applied Forestry 19:245-251.

Das, A., J. Battles, P. J. van Mantgem, and N. L. Stephenson. 2008. Spatial elements of mortality risk in old-growth forests. Ecology 89:1744-1756.

Das, A., J. Battles, P. J. van Mantgem, and N. L. Stephenson. 2011. The contribution of competition to tree mortality in old-growth coniferous forests. Forest Ecology and Management 261:1203-1213.

Ford, E. D., and P. J. Diggle. 1981. Competition for light in a plant monoculture modelled as a spatial stochastic process. Annals of Botany 48:481-500.

Franklin, J. F., and C. T. Dyrness. 1988. Natural vegetation of Oregon and Washington. Oregon State University Press.

Franklin, J. F., H. H. Shugart, and M. E. Harmon. 1987. Tree death as an ecological process. BioScience 37:550-556.

Franklin, J. F., et al. 2002. Disturbances and structural development of natural forest ecosystems with silvicultural implications, using Douglas-fir forests as an example. Forest Ecology and Management 155:399-423.

Franklin, J. F., and R. Van Pelt. 2004. Spatial aspects of structural complexity in old-growth forests. Journal of Forestry 102:22-28.

Getzin, S., C. Dean, F. He, J. A. Trofymow, K. Wiegand, and T. Wiegand. 2006. Spatial patterns and competition of tree species in a Douglas-fir chronosequence on Vancouver Island. Ecography 29:671-682.

Getzin, S., T. Wiegand, K. Wiegand, and F. He. 2008. Heterogeneity influences spatial patterns and demographics in forest stands. Journal of Ecology 96:807-820.

Goreaud, F., and R. Pélissier. 2003. Avoiding misinterpretation of biotic interactions with the intertype $\mathrm{K}_{12}$-function: population independence vs. random labelling hypotheses. Journal of Vegetation Science 14:681-692. 
Grier, C. C., K. A. Vogt, M. R. Keyes, and R. L. Edmonds. 1981. Biomass distribution and above- and below-ground production in young and mature Abies amabilis zone ecosystems of the Washington Cascades. Canadian Journal of Forest Research 11:155-167.

Harmon, M. E., and R. J. Pabst. 2015. Testing predictions of forest succession using long-term measurements: $100 \mathrm{yrs}$ of observations in the Oregon Cascades. Journal of Vegetation Science 26:722-732.

He, F., and R. P. Duncan. 2000. Density-dependent effects on tree survival in an old-growth Douglas fir forest. Journal of Ecology 88:676-688.

Holzwarth, F., A. Kahl, J. Bauhus, and C. Wirth. 2013. Many ways to die - partitioning tree mortality dynamics in a nearnatural mixed deciduous forest. Journal of Ecology 101:220230.

Kashian, D. M., M. G. Turner, W. H. Romme, and C. G. Lorimer. 2005. Variability and convergence in stand structural development on a fire-dominated subalpine landscape. Ecology 86:643-654.

Kenkel, N. C. 1988. Pattern of self-thinning in jack pine: testing the random mortality hypothesis. Ecology 69:1017-1024.

Kenkel, N. C., M. L. Hendrie, and I. E. Bella. 1997. A longterm study of Pinus banksiana population dynamics. Journal of Vegetation Science 8:241-254.

Laessle, A. M. 1965. Spacing and competition in natural stands of sand pine. Ecology 46:65-72.

Larson, A. J., and D. Churchill. 2008. Spatial patterns of overstory trees in late-successional conifer forests. Canadian Journal of Forest Research 38:2814-2825.

Larson, A. J., and J. F. Franklin. 2010. The tree mortality regime in temperate old-growth coniferous forests: the role of physical damage. Canadian Journal of Forest Research 40: 2091-2103.

Loosmore, N. B., and E. D. Ford. 2006. Statistical inference using the $G$ or $K$ point pattern spatial statistics. Ecology 87: 1925-1931.

Lutz, J. A., and C. B. Halpern. 2006. Tree mortality during early forest development: a long-term study of rates, causes, and consequences. Ecological Monographs 76:257-275.

Lutz, J. A., A. J. Larson, T. J. Furniss, D. C. Donato, J. A. Freund, M. E. Swanson, K. J. Bible, J. Chen, and J. F. Franklin. 2014. Spatially nonrandom tree mortality and ingrowth maintain equilibrium pattern in an old-growth Pseudotsuga-Tsuga forest. Ecology 95:2047-2054.

Oliver, C. D., A. B. Adams, and R. J. Zasoski. 1985. Disturbance patterns and forest development in a recently deglaciated valley in the northwestern Cascade Range of
Washington, U.S.A. Canadian Journal of Forest Research 15:221-232.

Peet, R. K., and N. L. Christensen. 1987. Competition and tree death. BioScience 37:586-595.

R Core Team. 2014. R: a language and environment for statistical computing. R Foundation for Statistical Computing, Vienna, Austria. http://www.R-project.org/

Raventós, J., T. Wiegand, and M. De Luis. 2010. Evidence for the spatial segregation hypothesis: a test with nine-year survivorship data in a Mediterranean shrubland. Ecology 91: 2110-2120.

Segura, G., L. B. Brubaker, J. F. Franklin, T. M. Hinckley, D. A. Maguire, and G. Wright. 1994. Recent mortality and decline in mature Abies amabilis: the interaction between site factors and tephra deposition from Mount St. Helens. Canadian Journal of Forest Research 24:1112-1122.

Silver, E. J., S. Fraver, A. W. D'Amato, T. Aakala, and B. J. Palik. 2013. Long-term mortality rates and spatial patterns in an old-growth Pinus resinosa forest. Canadian Journal of Forest Research 43:809-816.

Sorrensen-Cothern, K. A., E. D. Ford, and D. G. Sprugel. 1993. A model of competition incorporating plasticity through modular foliage and crown development. Ecological Monographs 63:277-304.

Stephenson, N. L., P. J. van Mantgem, A. G. Bunn, H. Bruner, M. E. Harmon, K. B. O'Connell, D. L. Urban, and J. F. Franklin. 2011. Causes and implications of the correlation between forest productivity and tree mortality rates. Ecological Monographs 81:527-555.

Svoboda, M., S. Fraver, P. Janda, R. Bače, and J. Zenáhlíková. 2010. Natural development and regeneration of a Central European montane spruce forest. Forest Ecology and Management 260:707-714.

Vacek, S., and J. Leps. 1996. Spatial dynamics of forest decline: the role of neighbouring trees. Journal of Vegetation Science 7:789-798.

Ward, J. S., G. R. Parker, and F. J. Ferrandino. 1996. Longterm spatial dynamics in an old-growth deciduous forest. Forest Ecology and Management 83:189-202.

Wiegand, T., and K. A. Moloney. 2004. Rings, circles, and nullmodels for point pattern analysis in ecology. Oikos 104:209229.

Wolf, A. 2005. Fifty year record of change in tree spatial patterns within a mixed deciduous forest. Forest Ecology and Management 215:212-223.

Worrall, J. J., T. D. Lee, and T. C. Harrington. 2005. Forest dynamics and agents that initiate and expand canopy gaps in Picea-Abies forests of Crawford Notch, New Hampshire, USA. Journal of Ecology 93:178-190.

\section{Supplemental Material}

\section{Ecological Archives}

The Appendix is available online: http://dx.doi.org/10.1890/15-0628.1.sm 